\title{
In vivo antiplasmodial activity of ZS-2A: a fraction from chloroform extract of Zizyphus spina-christi root bark against Plasmodium berghei berghei in mice
}

\author{
Bulus ADZU ${ }^{1,2 *}$, Abdul Kaita HARUNA ${ }^{2}$, Oluwakanyinsola Adeola SALAWU ${ }^{1}$, \\ Umar Adam KATSAYAL ${ }^{3}$ and Anoka NJAN ${ }^{4}$ \\ ${ }^{1}$ Department of Pharmacology and Toxicology, National Institute for Pharmaceutical Research and \\ Development, PMB 21, Abuja, Nigeria. \\ ${ }^{2}$ Department of Pharmaceutical and Medicinal Chemistry, Faculty of Pharmaceutical Sciences, Ahmadu Bello \\ University, Zaria, Nigeria. \\ ${ }^{3}$ Department of Pharmacognosy and Drug Development, Faculty of Pharmaceutical Sciences, Ahmadu Bello \\ University, Zaria, Nigeria. \\ ${ }^{4}$ Department of Pharmacology and Therapeutics, Faculty of Medicine, Mbarara University of Science and \\ Technology, P.O. Box 1410, Mbarara, Uganda. \\ * Corresponding author; Present address: Department of Pharmacy, Kampala International University, \\ Western Campus, Ishaka, P.O. Box 71, Bushenyi, Uganda, E-Mail: bulusadzu@yahoo.com
}

\begin{abstract}
Zizyphus spina-christi is used in ethnomedical practice for the treatment of fever. Bio-assay guided investigation of the plant's root bark was initiated and ZS-2A, a fraction from the chloroform extract of the material, eluted with hexane-ethylacetate (50:50) using flash column chromatography, was evaluated for in vivo antiplasmodial activity against Plasmodium berghei in mice. Four-day suppressive, curative effect against established infection and prophylactic models of antiplasmodial studies were used. The fraction (25, 50 and $100 \mathrm{mg} / \mathrm{kg}$, p.o.) showed a potent activity against the parasite in the suppressive and curative tests. The result suggests that ZS-2A may be a promising agent for malaria treatment.
\end{abstract}

(C) 2007 International Formulae Group. All rights reserved.

Keywords: Fraction ZS-2A, Zizyphus spina-christi, Plasmodium berghei berghei.

\section{INTRODUCTION}

Despite the increase threat of malaria to lives especially in Africa, success in controlling the disease is possible (White et al., 2004). Different approaches are currently being advocated to achieve this, which includes: exploring evidences of immunity, social science input, revisiting the abandoned vector control methods and investigation into traditionally used herbal medicines (Wright, 2005).

Zizyphus spina-christi Willd (Rhamnaceae) is a wild plant that can be domesticated. It grows in tropical Africa and Asia and has versed reported medicinal values (Burkill, 1997). Among the plant's popular ethnomedical uses is the treatment of fever (Al-Said, 1993). To the best of our knowledge, scientific basis for such usage has not been documented. As part of our continued evaluation of Zizyphus spina-christi root bark, we tested fraction (numbered ZS2A) from chloroform extract of the plant for its antiplasmodial activity against rodent plasmodia (Plasmodium berghei berghei) in vivo in mice for possible chemosuppressive effect against the parasite. The root bark of the plant was first sequentially extracted with four solvents (hexane, chloroform, ethylacetate and methanol) along their polarity using soxhlet extractor (Quickfit, England) and the extracts preliminarily tested for antiplasmodial activity. The chloroform extract that gave the highest activity was fractionated using flash column and evaluated for suppressive, curative and prophylactic activities against $P$. 
berghei berghei. The phytochemical composition of the chloroform extract was determined and its $\mathrm{LD}_{50}$ established.

\section{MATERIALS AND METHODS Plant material}

The plant material was collected at Midlu, Adamawa State, Nigeria between April and May, 2004. Its authentication, voucher specimen (NIPRD \#4108) preservation and extraction were as earlier reported (Adzu et al., 2007). Briefly, the root bark of the plant was carefully removed, cleaned and dried under shade. The dried root bark was ground into powder and $1.29 \mathrm{~kg}$ of the powdered material sequentially extracted to obtain hexane (ZS-1), chloroform (ZS-2), ethylacetate (ZS-3) and methanol (ZS-4) extracts. The combined extract of each solvent was concentrated and evaporated to dryness. The total yield of the extracts was $21.86 \%$ w/w of crude starting material.

\section{Phytochemical test}

The phytochemical composition of the chloroform extract was determined using standard procedures (Harborne, 1998). TLC was also carried out to determine spot zones which were viewed under UV light (254/365nm Eagle Scientific Ltd, UK).

\section{Fractionation of chloroform extract}

Ten grams of the chloroform extract (ZS-2) were mixed with $15 \mathrm{~g}$ of silica gel (Aldrich Chemical; 230-400 mesh) and loaded onto a flash column containing another $100 \mathrm{~g}$ of silica gel. It was then flushed with hexane, and eluted with gradient of ethylacetate in hexane, then methanol in multiples of $100 \mathrm{ml}$, using pump (ABM, Germany). Each of the fractions consisting of $100 \mathrm{ml}$ was individually collected. A total of 34 fractions (100 mL each) were collected and combined into six main groups (ZS-2A...ZS-2F) on the basis of their TLC profiles. These combined fractions (ZS-2A to ZS-2F) were concentrated over water bath and allowed to evaporate to dryness at room temperature. The fractions were preliminarily tested for antiplasmodial potency and ZS-2A which gave the most potent effect was fully evaluated.

\section{Animals}

Four weeks old albino mice obtained from Animal Facility Centre, NIPRD, Abuja, were used for the study. They were housed in plastic cages with saw dust as beddings and given food and water ad libitum. The mice were used in accordance with NIH Guide for the Care and Use of Laboratory Animals; NIH Publication (No 83-23) revised (1985) and NIPRD's Standard Operation Procedures (NIPRD-SOPs).

\section{Acute toxicity test}

The $\mathrm{LD}_{50}$ of the fraction was tested in order to determine the safety of the agent using Lorke's (1983) method. Briefly, ZS-2A was administered in geometric doses of 10 , 100 and $1000 \mathrm{mg} / \mathrm{kg}$ i.p. to four groups of mice $(\mathrm{n}=3)$. Another mouse was given normal saline to serve as the control and all the mice were kept under same conditions and observed for toxic signs and mortality for $24 \mathrm{~h}$.

\section{Rodent parasite (Plasmodium berghei berghei)}

The rodent parasite was sourced from National Institute for Medical Research (NIMR), Lagos, Nigeria by a co-author (U.A. Katsayal) and kept at Department of Veterinary Parasitology and Entomology, Ahmadu Bello University, Zaria, Nigeria. The parasites were kept alive by continuous reinfestation (i.p.) in mice (Calvalho et al., 1991) every 4 days. The reinfected mice were moved to the Department of Pharmacology and Toxicology, NIPRD, Abuja where the study was carried out. Prior to the commencement of the study, one of the infected mice was kept and observed to reproduce diseases similar to human infection (English et al., 1996).

\section{Chemicals and test agents}

All the chemicals used for the extraction, fractionation and chromatography were of analar grade and were purchased from Sigma-Aldrich representative in Nigeria (Zayo International Ltd, Jos, Nigeria). ZS-2A was prepared as aqueous tragacanth (a biologically inert surfactant) and were freshly prepared prior to each experiment.

\section{Antiplasmodial studies Suppressive test}

A modification of the classical 4-day earlier infection method (Peters et al., 1993; Okokon et al., 2006) was used for the test. Twenty five mice were inoculated as follows: 
A donor mouse with parasitaemic level of $(++)=11-100$ parasites per 100 thick film fields (WHO, 1985) was anaesthetised with chloroform. Blood $(1 \mathrm{ml})$ was collected through cardiac puncture with needle and syringe and made up to $20 \mathrm{ml}$ with saline. All the mice received $0.2 \mathrm{ml}$ of the diluted inoculum i.p. and were then group into groups $1-5(n=5)$ keeping the groups mean weight as near as possible. Group 1 was not treated and served as negative control. Groups $2-4$ received ZS-2A (25, 50 and $100 \mathrm{mg} / \mathrm{kg}$, p.o.) while group 5 was treated with chloroquine (5 $\mathrm{mg} / \mathrm{kg}$, s.c.), all on the first day $\left(\mathrm{D}_{0}\right)$. Treatment then continued daily $\left(D_{1}-D_{3}\right)$ until $\mathrm{D}_{4}$ when blood was collected from tail of each mouse and smeared onto a microscopic slide to make a film (Saidu et al., 2000). The films were fixed with methanol, stained with $4 \%$ Giemsa at pH 7.2 for 45 min (Saidu et al., 2000) and parasitaemia (WHO, 1994) examined microscopically (Kirby et al., 1993).

\section{Rane (curative) test}

The inoculation and treatment protocols used for the Rane test (Ryley and Peters, 1970) were similar to the suppressive test described above, except that in this test, treatment started on $\mathrm{D}_{3}$ after infection was established. On $\mathrm{D}_{3}$, a pretreatment blood smear of each mouse was collected and the mice were treated as described above. Treatment then continued daily $\left(D_{4}-D_{6}\right)$ until $\mathrm{D}_{7}$ when post treatment blood smears were collected and examined for parasite suppression. The mice were observed for 30 days and mean survival time of each grouped recorded (Adzu et al., 2003).

\section{Repository test}

The ability of ZS-2A to exhibit prophylactic activity was tested using the residual infection procedure (Peters, 1965). In this test, treatment (as described above) was initiated on $\mathrm{D}_{0}$ and continued till $\mathrm{D}_{4}$ when the mice were all infected with the parasite as earlier described. Smears were then made from each mouse $72 \mathrm{~h}$ after treatment (Abatan and Makinde, 1986) and increase/decrease in parasitaemia determined. The pre- and posttreatment body weights were taken.

\section{Data analysis}

Results were expressed as mean \pm SEM. Student t-test was used to analyse the data between groups and Analysis of Variance (ANOVA) among groups. $\mathrm{P}<0.05$ was considered significant in all cases.

\section{RESULTS \\ Phytochemical test}

The chloroform extract was found to contain carbohydrates $(+++)$, resins $(++)$, saponins $(++)$, terpenes $(+++)$ and traces of alkaloids $(+)$.

\section{Acute toxicity tests}

There was no mortality recorded in the mice, even in the ones that were $1000 \mathrm{mg} / \mathrm{kg}$, p.o. This indicates that the experimental doses used are relatively safe.

\section{Suppressive activity}

Percent inhibition of parasitaemia by ZS-2A was calculated as:

$\frac{\text { PC }- \text { PT }}{\text { PC }} \times 100$ (Hilou et al., 2006),

where $\mathrm{PC}=$ parasitaemia in control, and $\mathrm{PT}=$ parasitaemia in treated group.

The result is presented in Table 1 . The fraction exhibited potent dose dependent activity in the test.

\section{Curative effect}

The fraction was able to reduce the parasitaemia observed in the pretreatment data, but didn't totally clear the parasite after the termination of dosing. The mice survival was improved from the average of less than 10 days in the control group to over 3 weeks in the group that received $100 \mathrm{mg} / \mathrm{kg}$. However, except in the chloroquine (CQ) group, mortality was not totally abolished at the end of 30 days duration of observation (Table 2).

\section{Prophylactic effect}

ZS-2A failed to exhibit significant prophylactic effect since the parasitaemia remained high. It showed some improvement, but didn't totally prevent loss in body weight (Table 3). The plausible cause of this is discussed. 
Table 1: Effect of ZS-2A against $P$. bergei infection in mice on suppressive test.

\begin{tabular}{lccc}
\hline Treatment & $\begin{array}{c}\text { Dose } \\
(\mathbf{m g} / \mathbf{k g}, \mathbf{p . o} .)\end{array}$ & $\begin{array}{c}\text { Parasitaemia count } \\
\mathbf{D}_{\mathbf{4}}\end{array}$ & \% Inhibition \\
\hline Control & - & $19.2 \pm 4$ & - \\
ZS-2A & 25 & $11.4 \pm 2$ & $40.63^{*}$ \\
& 50 & $8 \pm 2$ & $58.33^{*}$ \\
CQ & 100 & $6.6 \pm 2$ & $65.63^{*}$ \\
* indicates significant difference $(\mathrm{p}<0.05) ;$ & $3 \pm 1$ & $84.38^{*}$ \\
\hline
\end{tabular}

* indicates significant difference $(\mathrm{p}<0.05)$; $\mathrm{D}_{4}$ = Day 4 after inoculation. CQ = chloroquine

Table 2: Effect of ZS-2A against $P$. bergei infection in mice during established infection (Curative test).

\begin{tabular}{lcccc}
\hline Treatment & $\begin{array}{c}\text { Dose } \\
\text { (mg/kg, p.o.) }\end{array}$ & \multicolumn{2}{c}{ Parasitaemia count } & Survival time \\
\cline { 3 - 4 } & - & $\mathbf{D}_{3}$ & $\mathbf{D}_{7}$ & (Days) \\
\hline Control & 25 & $16.2 \pm 0$ & $23.4 \pm 4$ & $9.6 \pm 2$ \\
ZS-2A & 50 & $18.4 \pm 5$ & $11.6 \pm 2$ & $12.4 \pm 3$ \\
& 100 & $17.6 \pm 5$ & $8.6 \pm 1^{*}$ & $20.4 \pm 3$ \\
& 5 & $18.2 \pm 3$ & $6 \pm 2^{*}$ & $25.4 \pm 2$ \\
CQ & $20.2 \pm 2$ & $2.6 \pm 1^{*}$ & 30 \\
\hline * indicates significant difference $(\mathrm{p}<0.05) ; \mathrm{D}_{3}=$ Day 3 and $\mathrm{D}_{7}=$ Day 7 after inoculation. $\mathrm{CQ}=$ chloroquine.
\end{tabular}

Table 3: Prophlactic effect of ZS-2A against $P$. bergei infection in mice (Repository test).

\begin{tabular}{lcccc}
\hline Treatment & Dose & Parasitaemia count & \multicolumn{2}{c}{ Body Weights (g) } \\
\cline { 3 - 5 } & (mg/kg, p.o.) & $\mathbf{D}_{\mathbf{7}}$ & $\mathbf{D}_{\mathbf{0}}$ & $\mathbf{D}_{\mathbf{7}}$ \\
\hline Control & - & $26.3 \pm 4$ & $23.15 \pm 2$ & $19.2 \pm 2$ \\
ZS-2A & 25 & $24.7 \pm 5$ & $22.92 \pm 2$ & $20 \pm 1$ \\
& 50 & $17.4 \pm 3$ & $23.17 \pm 3$ & $21.67 \pm 2$ \\
& 100 & $9.4 \pm 3^{*}$ & $25.83 \pm 2$ & $23 \pm 0$ \\
CQ & 5 & $7.6 \pm 4^{*}$ & $23.12 \pm 2$ & $22.6 \pm 2$ \\
\hline
\end{tabular}

\section{DISCUSSION}

The rodent parasite (P. berghei) discovered by Vinckey and Lips in 1948 have been used in studying the activity of potential antimalarials in mice (Thomas et al., 1998) and of recent, in rats (Pedroni et al., 2006). On the other hand, plants have proved to be sources of antimalarial agents, especially with the success of quinine isolated from the Peruvian Cinchona bark and artemisinin from Artemisia annua.

We chosed 4-week old mice for the study so as to exclude the effect of anaemia in the old mice and the possible changes it may induce (Pierrot et al., 2003). We opted for this in vivo model because it takes into account any prodrug effect and the likelihood of immune system in controlling infection (Waako et al., 2005). Oral dosing of ZS-2A was used, to replicate the ethnomedical method of administration and the likely route during clinical evaluation.

From the results, the fraction (ZS-2A) gave significant effect on both suppressive and curative test. Agents with suppressive activity against $P$. berghei were known for antimalarial activity (Calvalho et al., 1991). The fraction however failed to exhibit significant repository effect in the groups of mice that received low doses. This can be attributed to short duration of action of ZS2A, perhaps limited by rapid metabolism. It can also be due to the in vivo model used, which lacks the insect vector, and the manner of inoculation and the doses used that result in rapid infection of the erythrocytes (Ager, 1984) without the parasite going through the liver stages. Another possibility was that ZS2A might have acted through metabolic activation of the immune system (Waako et 
al., 2005) and so parasite clearance could not be total. There is also the fact that not all antimalarials are completely active in $P$. berghei model (Dow et al., 1998).

However, Zizyphus spina-christi is used in areas where malaria is endemic and individuals might possess at least some degree of immunity in which relief may in addition be symptomatic. The fraction might have probably acted like antimalarial plants in their crude form, acting mainly by causing elevation of red blood cell oxidation (Etkin, 1997) and/or by inhibiting protein synthesis (Kirby et al., 1989).

It is evident based on these findings that ZS-2A is a potential antiplasmodial agent, justifying its folkloric usage as an antimalarial (Al-Sad, 1993), indicative of its potential as a chemotherapeutic antimalarial. The activity may be attributed to either the terpenes of traces of alkaloids detected in the parent chloroform extract. Previous antiplasmodial screenings of plant substances have implicated terpenes, alkaloids and flavonoids (Phillipson and Wright, 1990; Christensen and Kharazmi, 2001). In addition, our earlier studies have shown that crude aqueous extract of Zizyphus spina-christi root bark has central analgesic and sedative effects (Adzu and Haruna, 2007). Agents with such activity were reported to provide relief to malaria patients (AddaeKyeremu et al., 2001).

\section{ACKNOWLEDGEMENTS}

This work (which was presented at the African Malaria Network Trust (AMANET): Fifth Biennial Scientific Conference (February 2007, Zanzibar, Tanzania), was taken from a thesis submitted to Department of Pharmaceutical and Medicinal Chemistry, Faculty of Pharmaceutical Sciences, Ahmadu Bello University, Zaria, Nigeria by B. Adzu. The authors appreciate the contributions of Andrew Sule for running the column chromatography, Elisha Baba for the parasitaemia counts and Prof. K.S. Gamaniel who guided the initiation of this study.

\section{REFERENCES}

Abatan MO, Makinde MJ. 1986. Screening Azadirachta indica and Pisum sativum for possible antimalarial activities. $J$. Ethnopharmacol., 17: 85 -93.
Addae-Kyereme J, Croft S., Kendrick H, Wright CW. 2001. Antiplasmodial activities of some Ghanaian plants traditionally used for fever/malaria treatment and of some alkaloids isolated from Pleiocarpa mutica in vivo antimalarial activity of pleiocarpine. $J$. Ethnopharmacol., 76: 99-103.

Adzu B, Abbah J, Vongtau H, Gamaniel K. 2003. Studies on the use of Cassia singueana in malaria ethnopharmacy. $J$. Ethnopharmacol., 88: 261-267.

Adzu B, Haruna AK, Salawu OA, Sule A. 2007. Bioassay-guided evaluation of the antidiarrhoeal potentials of Zizyphus spina-christi root bark in rats. Int. J. Biol. Chem. Sci., 1: 15 - 20.

Adzu B, Haruna AK. 2007. Studies on the use of Zizyphus spina-christi against pain in rats and mice. Afri. J. Biotech., 6: 1317 1324.

Ager AL. 1984. Rodent malaria models. In Handbook of Experimental Pharmacology, Peters W, Richards WHG (eds). Springer-Verlag: Berlin; 225-264.

Al-Said MS. 1993. Traditional medicinal plants of Saudi Arabia. Amer. J. Chinese Med., 21: 291-298.

Baker JT, Borris RP, Carte B, Cardell GA, Soejarto DD, Gragg GM, Gupta MP, Iwu MM, Madulid DR, Tyler VE. 1995. Natural product discovery and development: New perspective on international collaboration. J. Natural Prod., 58: 1325-1325.

Burkill HM. 1997. The useful plants of West Tropical Africa. Vol. 4. Royal Botanic Gardens: Kew; 493-496.

Calvalho LH, Brandao MGL, Santos-Filho D, Lopes JLC, Krettli AU. 1991. Antimalarial activity of crude extracts from Brazalian plants studied in vivo in Plasmodium berghei-infected mice and in vitro against Plasmodium falciparum in culture. Braz. J. Med. Biol. Res., 24: 1113-1123.

Christensen SB, Kharazmi A. 2001. Antimalarial natural products: isolation, characterisation and biological properties. In Bioactive compounds from natural sources: isolation, characterization and biological properties, Tringali C (ed). Taylor \& Francis: London; 379-432. 
Dow GS, Reynoldson JA, Thomson RC. 1998. Plasmodium berghei: In vivo efficacy of albendazole in different rodent models. Exp. Parasitol. 88:154-156.

Elujoba T. 2005. Traditional medicinal plants and malaria (Book Review). African J. Compl. Altern. Med., 2: 206-207.

English MC, Waruiri C, Lightowler C, Murphy SA, Kirigha G, Marsh K. 1996. Hyponatraemia and dehydration in severe malaria. Arch. Dis. Childhood, 74: 201205.

Etkin NL. 1997. Antimalarial plants used by Hausa in northern Nigeria. Tropical Doctor, 27: 12-16.

Harborne JB. 1998. Phytochemical methods: a guide to modern techniques of analysis (3rd edn). Chapman and Hall: London.

Hilou A, Nacoulma OG, Guiguemde TR. 2006. In vivo antimalarial activities of extracts from Amaranthus spinosus L. and Boerhaavia erecta L. in mice. J. Ethnopharmacol., 103: 236-240.

Kumar KA, Singn S, Babu PP. 2006. Studies on the glycoprotein modification in erythrocyte membrane during experimental cerebral malaria. Exp. Parasitol., 114: 173-179.

Lorke D. 1983. A new approach for acute toxicity testing. Arch. Toxicol., 54: 275287.

Okokon JE, Ita BN, Udokpoh AE. 2006. Antiplasmodial activity of Cylicodiscus gabunensis. J. Ethnopharmacol., 107: $175-178$.

Olumese E, Amodu OK, Bjorkman A, Adeyemo AA, Gbadegesin RA, Walker O. 2002. Chloroquine resistance of Plasmodium falciparum is associated with severity of disease in Nigerian children. Trans. Royal Soc. Trop. Med. Hyg., 96: 418-420.

Peters W. 1965. Drug resistance in Plasmodium berghei Vincka and Lips 1948: Chloroquine resistance. Exp. Parasitol., 17: 80-89.

Peters W, Robinson BL, Tovey G, Rossier JC, Jefford CW. 1993. The chemotherapy of rodent malaria. I. The activities of some synthetic 1, 2, 4-trioxanes against chloroquine-sensitive and chloroquine resistant parasites. Part 3: Observations on 'Fenozan-50F' a di-fluorated 3, 3'spirocyclopentane 1, 2, 4-trioxane. Annals Trop. Med. Parasitol., 87: 111123.

Phillipsons JD, Wright CW. 1990. Antiprotozoal compounds from plants sources. Planta Medica, 57 553-559.

Pedroni HC, Bettoni CC, Spalding SM, Costa TD. 2006. Plasmodium berghei: Development of an irreversible experimental malaria model in wistar rats. Exp. Parasitol., 113: 193-196.

Pierrot C, Adam E, Lafitte S, Godin C, Dive D, Capron M, Khalife J. 2003. Agerelated susceptibility and resistance to Plasmodium berghei in mice and rats. Exp. Parasitol., 104: 81-85.

Ryley JF, Peters W. 1970. The antimalarial activity of some quinoline esters. Annals Trop. Med.Parasitol., 64: 209-222.

Saidu K, Onah J, Orisadipe A, Olusola A, Wambebe C, Gamaniel K. 2000. Antiplasmodial, analgesic, and antiinflammatory activities of the aqueous extract of the stem bark of Erythrina senegalensis. J. Ethnopharmacol., 71: 275-280.

Thomas AM, Van Der Wel AM, Thoma, AW, Janse CJ, Waters AP. 1998. Transfection systems for animal models of malaria. Parasitol. Today 14: 248-249.

Waako PJ, Gumede B, Smith P, Folb PI. 2005. The in vitro and in vivo antimalarial activity of Cardiospermum halicacabum L. and Momordica foelida Schumch. Et Thonn. J. Ethnopharmacol., 99: 137-143.

White N, Nosten F, Bjorkman A, Marsh K, Snow RW. 2004. WHO, the Global Fund, and medical practice in malaria treatment. The Lancet, 363: 1160.

Wright CW. 2005. Traditional antimalarials and the development of novel antimalarial drugs. J. Ethnopharmacol., 100: $67-71$. 